\title{
Exploring the expression profile of vitamin D receptor and its related long non-coding RNAs in patients with acute lymphoblastic leukemia
}

\author{
Akram Norouzi ${ }^{1,2}$ (1), Marzieh Motaghi ${ }^{3}$ (D), \\ Gholamhossein Hassanshahii,4 (10, Mahdieh Nazari-Robati2* (1)
}

\section{SUMMARY}

OBJECTIVE: Acute lymphoblastic leukemia (ALL) is the most common type of childhood cancer. Previous studies have indicated the involvement of vitamin D receptor (VDR) and related long noncoding RNAs (IncRNAs) signaling in the pathophysiology of several cancers. However, their contribution to ALL remains to be elucidated.

METHODS: In this case-control study, 30 patients with newly diagnosed ALL and 30 age- and sex-matched healthy children were selected. Then, the level of $25(\mathrm{OH})$ vitamin D and the expression of VDR and four VDR-related IncRNAs were assessed.

RESULTS: No significant difference in serum $25(\mathrm{OH})$ vitamin D was observed between patients with ALL $(20.42 \pm 6.5 \mathrm{ng} / \mathrm{mL})$ and healthy subjects $(25.45 \pm 11 \mathrm{ng} / \mathrm{mL}$ ). In addition, the expression of MALAT-1, HOTAIR, and P-21 was not statistically significant between the two groups. However, a significant reduction in VDR and H19 expression was observed in patients with ALL $(p<0.05)$.

CONCLUSIONS: $25(\mathrm{OH})$ vitamin D insufficiency was evident in both groups. VDR and H19 signaling might be contributed to the pathogenesis of $A L L$, which needs further investigations.

KEYWORDS: Acute lymphoblastic leukemia. Vitamin D. Vitamin D receptor. Long non-coding RNA.

\section{INTRODUCTION}

Vitamin D deficiency is an important problem worldwide. As a fat-soluble vitamin, it is dominantly produced by human skin in response to solar ultraviolet-B radiation. Vitamin D has an important role in calcium homeostasis and bone metabolism. In addition, its effects on other cellular functions including cell differentiation, proliferation, apoptosis, and immunomodulation have been shown through studying some diseases ${ }^{1}$. Several studies have reported a negative association between serum 25-hydroxyvitamin $\mathrm{D}$ levels and risk of cancer ${ }^{2,3}$. Furthermore, vitamin D antitumorigenic effects have been shown in cell culture and animal studies ${ }^{4}$.
Cell response to active vitamin $\mathrm{D}$ is relied on the level of vitamin $\mathrm{D}$ receptor (VDR) expression. VDR is a member of steroid-thyroid-retinoid receptor superfamily of ligand-activated transcription factors ${ }^{4}$. After binding of vitamin D to $\mathrm{VDR}$, this receptor is dimerized with retinoid $\times$ receptor and the complex will bind to vitamin $\mathrm{D}$ receptor elements (VDREs) throughout the genome. It has been suggested that many VDREs are placed in noncoding regions of DNA. These sequences have no protein coding potential and are transcribed to noncoding RNAs including short and long ncRNA (lncRNAs) based on their size. LncRNAs, which are larger

\footnotetext{
${ }^{1}$ Student Research Committee, Kerman University of Medical Sciences, - Kerman, Iran.

${ }^{2}$ Department of Clinical Biochemistry, Faculty of Medicine, Kerman University of Medical Sciences - Kerman, Iran.

${ }^{3}$ Department of Hematology and Blood Banking, Kerman University of Medical Sciences - Kerman, Iran.

${ }^{4}$ Molecular Medicine Research Center, Research Institute of Basic Medical Sciences, Rafsanjan University of Medical Sciences - Rafsanjan, Iran.

*Corresponding author: mnazari@kmu.ac.ir

Conflicts of interest: the authors declare there is no conflicts of interest. Funding: This study was financially supported by Student Research Committee, Kerman University of Medical Sciences (grant no. 98000891).

Received on June 28, 2021. Accepted on July 03, 2021.
} 
than 200 bases in length, have pivotal roles in transcriptional and post-transcriptional regulation of genes. In this regard, some studies have shown the regulatory effects of several IncRNAs on VDR expression ${ }^{5,6}$.

As the most common pediatric cancer, leukemia accounts for $30 \%$ of all cancers occur in children. About three-quarters of leukemia diagnoses are acute lymphoblastic leukemia (ALL) ${ }^{7}$. ALL appears with defects in lymphoid cells differentiation and abnormal proliferation in bone marrow, peripheral blood, and extramedullary sites ${ }^{8}$. There have been limited studies evaluating vitamin D status in patients with ALL. In this case, a recent investigation has shown low levels of vitamin D in newly diagnosed ALL subjects in Pakistani population'. The prevalence of vitamin D deficiency in ALL survivors treated with conventional chemotherapy or hematopoietic cell transplantation was also reported in another study ${ }^{10}$. However, to our knowledge, no study has assessed the level of VDR and VDR-related lncRNAs expression in ALL. Therefore, this study was conducted to assess serum vitamin $\mathrm{D}$ level as well as the expression of VDR and four IncRNAs including H19, MALAT-1, P-21, and HOTAIR, which are associated with VDR in patients with newly diagnosed ALL.

\section{METHODS}

\section{Human subjects}

This case-control study consisted of 30 children with newly diagnosed ALL and 30 healthy volunteers (gender/age matched). All patients were selected from Afzalipour hospital (Kerman, Iran) during 2017 to 2019. They were 17 (56.7\%) males and 13 $(43.3 \%)$ females, with age ranging from 1 to 9 years. In order to be eligible to participate in this study, patients must meet the following criteria:

1. Having informed consent signed by their parents;

2. Having newly diagnosed ALL; and

3. Not having prior treatment (neither chemotherapy nor radiotherapy). Diagnosis was established according to standard morphologic, cytochemical, and cytogenetic criteria by a leukemia hematopathologist. All procedures of this research were approved by the Ethics Committee of Kerman University of Medical Sciences (IR.KMU. REC.1399.345).

\section{Collection of blood samples and PBMCs isolation}

Five milliliters of blood specimen was withdrawn from patients as well as controls in heparinized tubes. Using Ficoll-Hypaque solution gradient, peripheral blood mononuclear cells (PBMCs) were separated. In brief, blood was diluted and mixed with phosphate-buffered saline and then the mixture was gently added to Ficoll-Hypaque solution. After centrifugation at $800 \mathrm{~g}$ for $20 \mathrm{~min}$, PBMCs were found on the upper layer of the separation fluid, while other blood cells including RBCs and granulocytes remained at the bottom.

\section{Serum 25-hydroxy vitamin D measurement} Within $1 \mathrm{~h}$ of specimen collection, $2 \mathrm{~mL}$ of blood was centrifuged at 2,500 RPM for $20 \mathrm{~min}$. Serum was withdrawn and transferred into tubes. Then, $25(\mathrm{OH})$ vitamin D concentration was measured using $25(\mathrm{OH})$ Vitamin D ELISA kit (Monobind Inc., USA) and according to the manufacturer's recommendations.

\section{RNA extraction and quantitative real-time PCR}

Total RNA extraction was performed using Trizol reagent (Invitrogen, USA) and complementary DNA (cDNA) was synthesized according to the manufacturer's recommendations (Takara, Japan). Then, RNA concentration and purity were analyzed by a NanoDrop spectrophotometer (Thermo Scientific, USA). Quantitative Real-time polymerase chain reaction (PCR) analysis was performed in a $10-\mu \mathrm{L}$ final reaction volume using SYBR Green master mix (Amplicon, Denmark). Specific primers were designed using online Primer-Blast tool. Primer sequences and characteristics are provided in Table 1. The amplification was conducted as follows: $95^{\circ} \mathrm{C}$ for $15 \mathrm{~min}$ followed by 35 cycles of $40 \mathrm{~s}$ at $95^{\circ} \mathrm{C}, 25 \mathrm{~s}$ at $62^{\circ} \mathrm{C}$, and $15 \mathrm{~s}$ at $72^{\circ} \mathrm{C}$. A melting curve from $55^{\circ} \mathrm{C}$ to $100^{\circ} \mathrm{C}$ was recorded to detect potential unintended products. All reactions were run in duplicate with MIC Real-time PCR System (Bio Molecular Systems, Australia). RNA relative expression was calculated as fold-change using the comparative threshold cycle method (2$\triangle \Delta \mathrm{CT}$ ) with beta-2-microglobulin $(\beta 2 \mathrm{M})$ serving as the internal control gene.

\section{Statistical analysis}

Statistical analysis was carried out using SPSS software version 19.0 (IBM, USA). Descriptive analysis was applied to test demographic variables. Independent t-test was used to compare vitamin D levels between the two groups. MannWhitney U test was applied to compare VDR and lncRNAs expression differences between control and ALL groups. The results of VDR and lncRNAs were presented as median with the interquartile range. Other data were expressed as mean \pm SD. For all tests, $p<0.05$ was considered as the level of significance. 


\section{RESULTS}

The participants' characteristics are summarized in Table 2 . The mean age of control group was $5 \pm 4$ years and of patient group was $6 \pm 4$ years. Each group contained 17 boys and 13 girls.

The mean serum level of $25(\mathrm{OH})$ vitamin D in ALL and control groups were $20.42 \pm 6.5$ and $25.45 \pm 11 \mathrm{ng} / \mathrm{mL}$, respectively, which was not statistically significant $(\mathrm{p}=0.057)$. Our data showed that $67 \%$ of control group and $92 \%$ of patient group had vitamin D insufficiency, which was considered as serum $25(\mathrm{OH})$ vitamin $\mathrm{D}$ level between 10 and $29 \mathrm{ng} / \mathrm{mL}$ in this study. Quantification of VDR messenger RNA level in the two groups demonstrated that the expression of VDR was significantly downregulated in patient group $(\mathrm{p}=0.045)$. In addition, assessment of relative expression of H19, MALAT-1, P-21, and HOTAIR in the two groups showed downregulation of H19 in ALL group, which was statistically significant $(\mathrm{p}=0.028)$. However, no significant difference was observed in other lncRNAs between patient and control groups ( $p>0.05$ ) (Figure 1).

\section{DISCUSSION}

In the present study, we measured the level of serum vitamin $\mathrm{D}$ and VDR and some of VDR-related lncRNAs expression in patients with ALL. Our findings demonstrated that the expression of VDR and H19 were markedly reduced in ALL subjects. Although the survival rate of ALL has increased from less than $10 \%$ in 1960 s to $90 \%$ today, it is still the main reason of death from cancer in young people ${ }^{11}$. Unraveling the risk factors that change in ALL may lead to disease prevention and improvement in the treatments. Vitamin D is one of these controversial factors that attracted a lot of attention because of its possible antiproliferative and pro-differentiating effects ${ }^{12}$. Several studies have shown the beneficial effects of vitamin $\mathrm{D}$ in some types of solid cancers and also some hematological malignancies ${ }^{13}$, but it remains poorly studied with respect to ALL.
Our findings showed a lower mean value of $25(\mathrm{OH})$ vitamin $\mathrm{D}$ in patients with ALL when compared to control group. However, their difference was not statistically significant. Similarly, Naz et al. observed that over $90 \%$ of patients with acute leukemia including ALL and acute myeloid leukemia (AML) had insufficient $25(\mathrm{OH})$ vitamin D levels. They also found that $25(\mathrm{OH})$ vitamin $\mathrm{D}$ insufficiency was more

Table 2. Comparison of general characteristics and laboratory features between control and ALL groups.

\begin{tabular}{l|c|c}
$\begin{array}{l}\text { Variables } \\
\text { Age (year) }\end{array}$ & $6 \pm 4$ & ALL group \\
\hline $\begin{array}{l}\text { Gender }(\%) \\
17 \text { males }(56.7 \%) \\
13 \text { females }(43.3 \%)\end{array}$ & $\begin{array}{c}17 \text { males }(56.7 \%) \\
13 \text { females }(43.3 \%)\end{array}$ \\
\hline $\begin{array}{l}\text { WBC } \\
\left(\times 10^{3} / \mu L\right)\end{array}$ & $7180 \pm 442$ & $15,980 \pm 5331$ \\
\hline $\begin{array}{l}25(\mathrm{OH}) \\
\text { vitamin D } \\
(\mathrm{ng} / \mathrm{mL})\end{array}$ & $25.45 \pm 11$ & $20.42 \pm 6.5$ \\
\hline
\end{tabular}

ALL: acute lymphoblastic leukemia; WBC: white blood cell count.

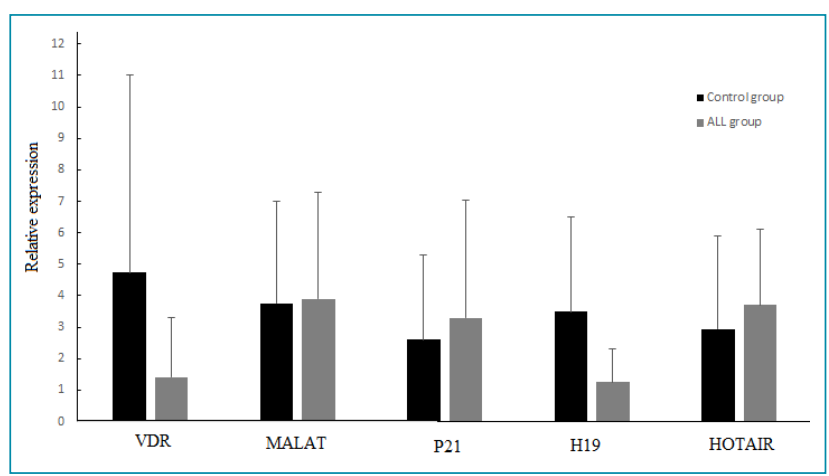

Figure 1. Expression of vitamin D receptor, H19, MALAT-1, P-21, and HOTAIR related long noncoding RNAs levels in the patients with acute lymphoblastic leukemia and healthy control participants. Vitamin D receptor and $\mathrm{H} 19$ expression demonstrated significant differences between patient and control group. Data were presented as median with the interquartile range. ${ }^{*} p<0.05$ compared with healthy control.

Table 1. Nucleotide sequences and characteristics of primers used for expression analysis.

\begin{tabular}{l|c|c|c|c|c|c|c} 
Gene & Forward primer $\left(5^{\prime}-3^{\prime}\right)$ & $\mathrm{T}_{\mathrm{m}}$ & $\mathrm{GC} \%$ & Reverse primer $\left(5^{\prime}-3^{\prime}\right)$ & $\mathrm{T}_{\mathrm{m}}$ & $\mathrm{GC} \%$ & $\begin{array}{c}\text { Product } \\
\text { size }(\mathrm{bp})\end{array}$ \\
\hline VDR & TTGCCATACTGCTGGACGC & 60.7 & 58 & GGCTCCCTCCACCATCATT & 59.1 & 58 & 102 \\
\hline B2M & CTCCGTGGCCTTAGCTGTG & 60.4 & 63 & TTIGGAGTACGCTGGATAGCCT & 61.2 & 50 & 69 \\
\hline MALAT-1 & GCTCTGTGGTGTGGGATTGA & 60.0 & 55 & GTGGCAAAATGGCGGACTTT & 60.0 & 50 & 179 \\
\hline HOTAIR & GCACCGCTTTTCTAACTGGC & 60.1 & 55 & CAGGGTCCCACTGCATAATCA & 59.8 & 52 & 141 \\
\hline P-21 & AGGACCAGAATAACCCGAGC & 59.2 & 55 & CTGGGGTCCAGGATGCATAG & 59.6 & 60 & 109 \\
\hline H19 & CACGGCTTTCTCAGGCCTAT & 59.8 & 55 & TACAGCGTCACCAAGTCCAC & 60.0 & 55 & 238 \\
\hline
\end{tabular}


pronounced in patients with ALL as compared to those with AML 9 . Similarly, Bhattacharya et al. reported that $84.95 \%$ of children with ALL in North India were deficient in vitamin $\mathrm{D}$ and that these children were at a higher risk of developing complications during treatment of ALL ${ }^{14}$.

In animal studies, vitamin $\mathrm{D}$ has been shown to have antitumor actions in many tissues, which have potentiated this vitamin as an anticancer agent ${ }^{6}$. However, the molecular basis by which this vitamin may be involved in ALL is not understood. Generally, vitamin $\mathrm{D}$ exerts its actions through its binding with VDR, which is expressed in most cells in the body. Comprehensive genomewide in silico and transcriptome screens have reported some VDR activities, including suppression of cells proliferation and migration, enhancement of cells adhesion, and induction of apoptosis in cells $s^{15}$. However, few studies have evaluated VDR roles or resistance to its signaling pathway in hematological malignancies ${ }^{14}$. Our results showed that VDR expression was downregulated in ALL samples compared to normal samples. This finding is consistent with similar observations made by several studies ${ }^{16}$.

LncRNAs are involved in various cellular processes, including cell proliferation, migration, invasion, and transformation. Accumulating data suggest that dysregulation of lncRNAs is involved in tumorigenesis ${ }^{17}$. A recent study showed that the balance in several oncogenic to tumor-suppressing lncRNAs expression was disturbed in VDR null mice, which resulted in a higher predisposition of these animals to cancer ${ }^{18}$. In another study, Chen et al. showed a reciprocal relation between VDR and H19 expression in colon cancer cells. They reported the regulatory effect of $\mathrm{H} 19$ on VDR expression through microRNA 675-5p and also H19 expression inhibition by VDR signaling ${ }^{19}$. Overexpression of MALAT-1 was reported in patients with acute monocytic leukemia by Huang et al. They also observed that MALAT-1 knocking-down inhibited leukemia cell proliferation and induced apoptosis ${ }^{20}$. Hao et al. reported upregulation of HOTAIR in de novo patients with AML and its role in cell proliferation in vitro ${ }^{21}$. Downregulation of P-21, a tumor suppressor and post-transcriptional regulator, was observed in patients with chronic lymphocytic leukemia, whereas its low expression was correlated with some clinical outcomes ${ }^{17}$. Based on these reports, we measured the expression of four VDR-related lncRNAs including H19, MALAT-1, P-21, and HOTAIR in patients with ALL. However, we did not find any significant difference in MALAT-1, HOTAIR, and P-21 expression between ALL and healthy group.
According to our data, we observed a significant downregulation of $\mathrm{H} 19$ expression in patients with ALL compared to control group. As a paternally imprinted gene, H19 locates in chromosome $11 \mathrm{p} 15.5^{22}$. It has been reported that $\mathrm{H} 19$ plays important roles in embryonic development, growth control, glucose metabolism, and tumor development. Most studies in human have reported upregulation of H19 lncRNA in cancer and considered it an oncogenic lncRNA. However, Hao et al. reported the first evidence of tumor suppressor activity of $\mathrm{H} 19$ by transfection of H19 cDNA into G401-transformed kidney cells and observing loss of tumorigenicity of these cells ${ }^{23}$. In another study, Yoshimizu et al. showed the tumor suppressor effect of $\mathrm{H} 19$ using in vivo murine models of tumorigenesis ${ }^{24}$. Supporting our findings, a study by Schultheiss et al. showed that H19 expression in hepatocellular carcinoma was lower than normal or nontumorous adjacent tissues and concluded that $\mathrm{H} 19$ suppressed hepatocarcinogenesis and hepatoma cell growth $^{25}$. Therefore, H19 can be considered both oncogene and tumor suppressor IncRNA.

There are some possible reasons for these discrepancies observed between our results and other data. First, previous studies were performed in different racial groups who differed in genetic factors. Second, we did this study in a small sample size due to low incidence rate of leukemia $(3.6 / 100,000)$ that might increase the likelihood of a Type II error. Third, cancer type and stage were not the same in all mentioned studies.

\section{CONCLUSIONS}

In conclusion, this is the first study showing the downregulation of VDR and H19 expression in patients with ALL. Our results reinforce the potential roles of VDR and H19 as biomarkers in the pathogenesis of ALL. However, the inconsistent results in VDR and H19 expression suggest a necessity for further investigations to explore VDR- and H19-related signaling pathways in the pathogenesis of ALL.

\section{AUTHORS" CONTRIBUTIONS}

MNR: Conceptualization, Supervision, Funding acquisition. AN: Investigation, Writing - original draft. MM: Investigation. GH: Writing - review \& editing.

\section{REFERENCES}

1. Berridge MJ. Vitamin D cell signalling in health and disease. Biochem Biophys Res Commun. 2015;460(1):53-71. https:// doi.org/10.1016/j.bbrc.2015.01.008
2. Tretli S, Hernes E, Berg JP, Hestvik UE, Robsahm TE. Association between serum $25(\mathrm{OH}) \mathrm{D}$ and death from prostate cancer. Br J Cancer. 2009;100(3):450-4. https://doi.org/10.1038/sj.bjc.6604865 
3. Engel P, Fagherazzi G, Boutten A, Dupré T, Mesrine S, Boutron-Ruault $M C$, et al. Serum $25(\mathrm{OH})$ vitamin $D$ and risk of breast cancer: a nested case-control study from the French E3N cohort. Cancer Epidemiol Biomarkers Prev. 2010;19(9):2341-50. https://doi.org/10.1158/1055-9965. EPI-10-0264

4. Feldman D, Krishnan AV, Swami S, Giovannucci E, Feldman BJ. The role of vitamin $D$ in reducing cancer risk and progression. Nat Rev Cancer. 2014;14(5):342-57. https://doi.org/10.1038/ nrc3691

5. Issa LL, Leong GM, Eisman JA. Molecular mechanism of vitamin D receptor action. Inflamm Res. 1998;47(12):451-75. https:// doi.org/10.1007/s000110050360

6. Jiang YJ, Bikle DD. LncRNA: a new player in $1 \alpha, 25(\mathrm{OH})(2)$ vitamin $\mathrm{D}(3)$ NDR protection against skin cancer formation. Exp Dermatol. 2014;23(3):147-50. https://doi.org/10.1111/ exd.12341

7. Belson $M$, Kingsley B, Holmes A. Risk factors for acute leukemia in children: a review. Environ Health Perspect. 2007;115(1):13845. https://doi.org/10.1289/ehp.9023

8. Terwilliger T, Abdul-Hay M. Acute lymphoblastic leukemia: a comprehensive review and 2017 update. Blood Cancer J. 2017;7(6):e577. https://doi.org/10.1038/bcj.2017.53

9. Naz A, Qureshi RN, Shamsi TS, Mahboob T. Vitamin D levels in patients of acute leukemia before and after remissioninduction therapy. Pak J Med Sci. 2013;29(1):10-4. https:// doi.org/10.12669/pjms.291.2764

10. Simmons JH, Chow EJ, Koehler E, Esbenshade A, Smith LA, Sanders J, et al. Significant 25-hydroxyvitamin D deficiency in child and adolescent survivors of acute lymphoblastic leukemia: treatment with chemotherapy compared with allogeneic stem cell transplant. Pediatr Blood Cancer. 2011;56(7):1114-9. https://doi.org/10.1002/pbc.22949

11. Hunger SP, Mullighan CG. Acute lymphoblastic leukemia in children. N Engl J Med. 2015;373(16):1541-52. https://doi. org/10.1056/NEJMra1400972

12. Krishnan AV, Trump DL, Johnson CS, Feldman D. The role of vitamin $D$ in cancer prevention and treatment. Rheum Dis Clin North Am. 2012;38(1):161-78. https://doi.org/10.1016/j. rdc.2012.03.014

13. Kulling PM, Olson KC, Olson TL, Feith DJ, Loughran Jr TP. Vitamin $D$ in hematological disorders and malignancies. Eur J Haematol. 2017;98(3):187-97. https://doi.org/10.1111/ ejh.12818
14. Bhattacharya S, Verma N, Kumar A. Prevalence of vitamin D deficiency in childhood acute lymphoblastic leukemia and its association with adverse outcomes during induction phase of treatment. Nutr Cancer. 2020;72(8):1321-5. https://doi.org/ 10.1080/01635581.2019.1679196

15. Thorne J, Campbell MJ. The vitamin D receptor in cancer Proc Nutr Soc. 2008;67(2):115-27. https://doi.org/10.1017/ S0029665108006964

16. Shi Q, Han XP, Yu J, Peng H, Chen YZ, Li F, et al. Decreased vitamin $D$ receptor protein expression is associated with progression and poor prognosis of colorectal cancer patients. Int J Clin Exp Pathol. 2020;13(4):746-55. PMID: 32355523

17. Huarte $M$. The emerging role of IncRNAs in cancer. Nat Med. 2015;21(11):1253-61. https://doi.org/10.1038/nm.3981

18. Jiang YJ, Bikle DD. LncRNA profiling reveals new mechanism for VDR protection against skin cancer formation. J Steroid Biochem Mol Biol. 2014;144 PtA:87-90. https://doi.org/10.1016/j.jsbmb.2013.11.018

19. Chen S, Bu D, Ma Y, Zhu J, Chen G, Sun L, et al. H19 Overexpression induces resistance to $1,25(\mathrm{OH}) 2 \mathrm{D} 3$ by targeting VDR through miR-675-5p in colon cancer cells. Neoplasia. 2017;19(3):226-36. https://doi.org/10.1016/j.neo.2016.10.007

20. Huang JL, Liu W, Tian LH, Chai TT, Liu Y, Zhang F, et al. Upregulation of long non-coding RNA MALAT-1 confers poor prognosis and influences cell proliferation and apoptosis in acute monocytic leukemia. Oncol Rep. 2017;38(3):1353-62. https://doi.org/10.3892/or.2017.5802

21. Hao S, Shao Z. HOTAIR is upregulated in acute myeloid leukemia and that indicates a poor prognosis. Int J Clin Exp Pathol. 2015;8(6):7223-8. PMID: 26261618

22. Liu Y, He A, Liu B, Huang Z, Mei H. Potential role of IncRNA H19 as a cancer biomarker in human cancers detection and diagnosis: a pooled analysis based on 1585 subjects. Biomed Res Int. 2019;2019:9056458. https://doi.org/10.1155/2019/9056458

23. Hao Y, Crenshaw T, Moulton T, Newcomb E, Tycko B. Tumoursuppressor activity of H19 RNA. Nature. 1993;365(6448):764-7. https://doi.org/10.1038/365764a0

24. Yoshimizu T, Miroglio A, Ripoche MA, Gabory A, Vernucci M, Riccio A, et al. The H19 locus acts in vivo as a tumor suppressor. Proc Natl Acad Sci U S A. 2008;105(34):12417-22. https:// doi.org/10.1073/pnas.0801540105

25. Schultheiss CS, Laggai S, Czepukojc B, Hussein UK, List M, Barghash $A$, et al. The long non-coding RNA H19 suppresses carcinogenesis and chemoresistance in hepatocellular carcinoma. Cell Stress. 2017;1(1):37-54. https://doi.org/10.15698/cst2017.10.105 